\title{
Desenvolvimento turístico regional: Governança e territorialidade no caso da Oktoberfest Blumenau (Santa Catarina, Brasil)
}

\section{The regional tourist development: Governance and territoriality in the tourist product Oktoberfest/Blumenau (Santa Catarina, Brazil)}

\author{
Leonardo Furtado da Silva (SILVA, L. F. da) ${ }^{*}$ \\ Oklinger Mantovaneli Jr. (MANTOVANELI JÚNIOR, O.) ${ }^{* *}$ \\ Carlos Alberto Cioce Sampaio (SAMPAIO, C. A. C.)
}

\begin{abstract}
RESUMO - Este trabalho apresenta como objetivo caracterizar governança e territorialização no produto turístico Oktoberfest Blumenau, identificando suas fases desde o início, em 1984, e elementos de influência no desenvolvimento turístico regional. Resulta de estudo qualitativo analítico-descritivo amparado majoritariamente em fontes primárias por meio de entrevistas semiestruturadas (com gestores estratégicos do evento). Os dados foram correlacionados por meio da análise de conteúdo. Sinteticamente, os resultados do estudo demonstram que o evento passou por um conjunto de fases distintas e expressivas, aqui caracterizadas como territorialidades, propiciadas respectivamente por instâncias de governança, onde o poder público local, comunidade e a iniciativa privada possuem interesses e os mesmos precisam ser ajustados no planejamento e execução deste megaevento. Ou seja, padrões de pactuação para a consecução dos objetivos que dão sustentação ao evento e o caracterizam: fatores culturais, sociais e econômicos.
\end{abstract}

Palavras chave: Desenvolvimento Turístico Regional; Territorialidade; Governança; Oktoberfest Blumenau.

\footnotetext{
* Graduação em Turismo e Administração Hoteleira pela Universidade do Oeste de Santa Catarina (UNOESC), Mestrado e Doutorando em Desenvolvimento Regional pela Universidade Regional de Blumenau (FURB). Pesquisador do Núcleo de Políticas Públicas (NPP/FURB). Endereço para correspondência: Rua Antônio da Veiga, 140 - Victor Konder. CEP: 89012-900 - Blumenau (SC) - Brasil. Telefone para contato: (47) 3321-0522. E-mail: Leonardo.ppgdr@gmail.com

** Graduação em Relações Internacionais pela Universidade de Brasília (UNB), Mestrado em Administração pela Universidade Federal de Santa Catarina (UFSC), Doutorado em Sociologia pela Universidade Estadual Paulista (UNESP), Pós-doutorando em Planejamento e Gestão do Território na Universidade Federal do ABC (PGPGT), Professor do Programa de Pós-Graduação em Desenvolvimento Regional (PPGDR) e Coordenador do NPP/FURB. Endereço para correspondência: Rua Antônio da Veiga, 140 - Victor Konder. CEP: 89012-900 - Blumenau (SC) Brasil. Telefone para contato: (47) 33210522. E-mail: oklinger@furb.br

*** Graduação pela Pontifícia Universidade Católica (PUCSP) e Mestrado (UFSC) em Administração, Doutorado em Engenharia da Produção (UFSC) com sandwich em Economia Social (EHESS, França), Pós-Doutorado em Ecossocioeconomia (UACh, Chile) e Cooperativismo Corporativo (U.Mondragon, Espanha). Professor do Curso de Graduação em Turismo e dos Programas de Pós-Graduação (PPG) em Gestão Urbana (PUCPR) e PPG em Desenvolvimento Regional (FURB) e dos PPG em Meio Ambiente e Desenvolvimento e em Turismo (UFPR). Pesquisador CNPq. Coordenador Adjunto da Área em Ciências Ambientais. Endereço para correspondência: Rua Ver. Washington Mansur, 248, ap. 61 (Ahú). CEP: 80540-210 - Curitiba (PR) - Brasil. Telefone para contato: 41 9818-4124. E-mail: carlos.cioce@gmail.com.
} 


\begin{abstract}
The objective of this paper is to characterize the governance and territorial issues in the tourist product Oktoberfest Blumenau, identifying its phases from the beginning, in 1984, and elements of influence in regional touristic development. This study is based analytical-descriptive qualitative research, which used in mainly primary data through semi-structured interviews with strategic managers of the event. The data were correlated using content analysis. In summary, the results of this study demonstrate that the event had a series of distinct phases, characterized as expressions of territoriality, due to instances of governance, where the local government, community and private sector have the same interests and need to be set in the planning and implementation of this mega event. In other words, patterns of agreement for the achievement of objectives that support the event: cultural, social and economic dimensions.
\end{abstract}

Key words: Regional Tourist Development; Territoriality; Governance; Oktoberfest Blumenau. 


\section{INTRODUÇÃ̃O ${ }^{1}$}

Em qualquer setor, segmento ou atividade associada a vida humana e aos fatores de produção, as escolhas e os conflitos delas oriundas determinam intencionalidade entre os sujeitos de um contexto. As opções que se hegemonizam e perfazem aspecto importante do processo de desenvolvimento representam um recorte na agenda de alternativas. A opção por objetivar escolhas ante interesses confluentes ou difusos resulta em um fenômeno nominado por governança, hoje discutido por muitos autores da ciência política (administração pública e de empresas) e outras áreas correlatas. Para que este fenômeno se efetive é preciso compreender o papel de cada ator social envolvido com o contexto em foco, suas prioridades e interesses para a construção da pactuação e consequentemente do cenário desejado.

Este trabalho apresenta como objetivo principal caracterizar governança e também a territorialização no produto turístico Oktoberfest, a maior festa germânica das Américas (PMB, 2013), desde seu início, em 1984 até o presente, como elementos de influência no desenvolvimento turístico regional. Tem, portanto, como pano de fundo o turismo de eventos na expressão do maior megaevento do estado de Santa Catarina Brasil. Seja por suas particularidades, na cidade que o abriga, como por sua capacidade de "trasbordar para todo o estado", pautar a agenda turística de Santa Catarina em outubro, e produzir reflexos durante todo o ano. Seu amadurecimento abre um campo profícuo de hipóteses de trabalho e estudos para quem tem, como objeto, eventos de efetiva grandeza e substrato territorial, no Sul do Brasil, suas políticas públicas de turismo e ações empreendedoras subjacentes, com implicações para o homem, seu território, meio-ambiente, a cultura, a sociedade e economia de uma região.

Caracterizou-se como pesquisa qualitativa, exploratória no que tange à discussão proposta, analítica e descritiva. A coleta de dados foi amparada em fontes primárias e secundárias, sendo as primárias entrevistas semiestruturadas por roteiro com uso de gravador, transcritas e analisadas por análise de conteúdo. As fontes secundárias basicamente expressam levantamento de documentos no acervo da Fundação Cultural de Blumenau, na busca de informações que caracterizaram as distintas fases do

\footnotetext{
${ }^{1}$ Este trabalho é versão ampliada e atualizada de estudo preliminar apresentado no XI Seminário Internacional de Turismo - SIT 2009 e publicado em língua espanhola no periódico Estudios y Perspectivas em Turismo no ano de 2012.
} 
megaevento, aqui tomadas como territorialidades. Este megaevento teve três fases distintas que caracterizaram a sua territorialidade: no início (1984) seguiu a proposta de um grande evento da cultura germânica, com forte apelo cultural. Em um segundo momento (década de 1990), houve uma descaracterização em função da mercantilização do evento, o qual apresentou uma massificação e houve uma espécie de 'carnaval alemão" aonde a família e os aspectos culturais foram descaracterizados da proposta inicial. A terceira fase deste contexto, caracterizou-se pelo resgate da ênfase cultural alemã e da presença das famílias blumenauenses no evento, sem perder a prospecção de demanda de turistas, porém priorizando-se em sua organização e produtos, a cultura germânica (2004 até os dias atuais).

O universo de estudo compreendeu um panorama de muitos atores cuja quantificação foi variável e sobre os quais foi definida uma amostra a partir da etapa exploratória do estudo, buscando alguns atores estratégicos. A amostra considerada foi intencional, onde foram escolhidos atores em conformidade com as informações necessárias, relativas às 3 territorialidades identificadas e a problemática definida para o estudo. Dentre os critérios intencionais, além da atuação estratégica e do envolvimento com as três territorialidades identificadas, buscou-se a representação setorial, considerando atores do setor público, do setor privado (mercado) e da comunidade. Em 2008 foram entrevistados cinco representantes do grupo gestor do evento, sendo três representantes do setor público, um do setor privado e um da comunidade. Em 2013 foram revisitadas as fontes originais e analisadas informações em novas fontes secundárias no sentido de verificar a pertinência e atualidade dos resultados do estudo. A preocupação, presente, foi procurar verificar se uma nova fase de desenvolvimento se abriu, ou se a terceira territorialidade identificada permanecia em curso. Os limites do estudo referenciam-se na opção pela amostra estruturada, pelos tipos de fontes e dados escolhidos e pelo seu aporte técnico, além dos recortes temporais assumidos.

O artigo está estruturado da seguinte forma: apresentação do cenário da Oktoberfest e as suas fases (territorialidades), estudo conceitual através do referencial teórico, análise de dados sobre a festa e seus impactos para o desenvolvimento de Blumenau e do Vale do Itajaí. 


\section{DESENVOLVIMENTO REGIONAL}

O desenvolvimento regional está sendo analisado aqui a partir da perspectiva do desenvolvimento da atividade turística e mais especificamente em uma de suas mais importantes ramificações: o setor de eventos, uma forma de lazer e propulsora de desenvolvimento e que assim fica entendida dentro do contexto do desenvolvimento regional/local. Cardoso e Ribeiro (2002) afirmam que durante muito tempo foi ponto firme na teoria econômica que os investimentos em capital físico, humano e tecnologia eram os principais fatores de expansão econômica de uma região.

As alternativas regionais do desenvolvimento, observando-se as características locais de cada comunidade, município e/ou região, são fatores fundamentais para pensar o desenvolvimento com uma visão descentralizada, como aparece no desenvolvimento local: "Desenvolvimento local é um processo de mudança sócio-estrutural, mapeado sobre um território próximo, definido geograficamente pela própria escala do processo" (BOISIER, 2006, p. 70). Portanto, contemplando as potencialidades e as realidades locais, este processo define-se pelo caráter de endogenia, assim identificado por Boisier (2006, p. 70):

\footnotetext{
Caracteriza-se esse processo pelo seu caráter endógeno (autonomia, reinvestimento, inovação, identidade), pelo papel dos recursos, em especial aqueles não materiais do lugar, pelos agentes e suas relações, tanto diretas quanto medidas, pela escala e funcionalidade das organizações, pela cultura local, cujo produto é uma sinergia que causa um progresso sistemático do território (até condição de comunidade imaginada) e de cada um dos seres humanos que o habita (até atingir a condição de pessoa).
}

Nesse contexto, o desenvolvimento apresenta-se através da faceta interna de uma região (características), passando pelos valores naturais locais (cultura e meio ambiente), transportando-se até as características dos seus cidadãos e, dessa forma, unindo um território, suas vantagens e benefícios (visão holística) ao seu principal agente: o ser humano.

Partindo da ambiência da política pública, através da planificação do turismo de eventos, existem aspectos a serem contemplados e observados para posteriormente transformar ideias (organização e a exploração econômica do lazer) em ações: planejamento, recursos humanos, inclusão, pluralidade cultural e de ideias, preocupação ambiental, infraestrutura turística e urbana, conscientização sobre o turismo e o lazer. A 
partir deste cenário delineado, o lazer/eventos e a sua organização passam a ser encarados como uma forma de propulsão real do desenvolvimento regional com benefícios para os atores sociais envolvidos, bem como o atendimento de seus interesses, os quais poderão ser atendidos através da pactuação a qual deve ser propiciada pela governança, a qual será analisada a seguir.

\section{GOVERNANÇA}

Em qualquer forma de gestão é preciso haver uma consonância entre os atores envolvidos, bem como as formas regulatórias desta relação necessitam de harmonia. Tanto o setor público como o privado necessitam desta busca do consenso ao interesse comum dos protagonistas, podendo ser definida como uma pactuação para se atingirem objetivos que passam necessariamente pela análise para o atendimento de necessidades destes mesmos atores da sociedade: poder público, iniciativa privada e a comunidade (SAMPAIO, 2004). Nesta perspectiva temática podem-se identificar dois aspectos importantes para a sustentação do tema governança: sustentabilidade política e a sustentabilidade administrativa. É importante observar também a visão da Organização das Nações Unidas - ONU sobre o tema:

Governança é a totalidade das diversas maneiras pelas quais os indivíduos e as instituições, públicas e privadas, administram seus problemas comuns. É um processo contínuo pelo qual é possível acomodar interesses conflitantes ou diferentes e realizar ações cooperativas. Governança diz respeito não só a instituições e regimes formais autorizados a impor obediência, mas também a acordos informais que atendam aos interesses das pessoas e instituições (ONU, 1996, p. 2).

É importante observar a visão da ONU para que as mais diversas tendências de interpretação do tema sejam explicitadas em uma definição, expressando pluralidade de tendências e, portanto, interesses.

Dentro deste contexto vale ressaltar ainda o grau de complexidade do fenômeno que o termo apresenta, pois além dos atores sociais de uma comunidade que se envolvem em uma relação para ação visando convergência de interesses, é importante observar como a terminologia governança pública trata deste assunto. 
A partir deste termo bem definido, têm-se uma perspectiva maior sobre o fenômeno que retrata, pois além da convergência dos atores sociais em torno de um objetivo comum traçado ou mesmo consequente, percebe-se que a governança aborda com maior intensidade os aspectos sociais, ambientais, alicerçados nos político-legais para que efetivamente ocorra. Indo ao encontro desta última discussão, é fundamental haver uma distinção entre o termo governança, já apresentado nesta pesquisa e a governabilidade, pois fora do ambiente acadêmico, pode haver distorções se não devidamente conceituados:

A governabilidade refere-se mais a dimensão estatal do exercício do poder. Diz respeito a "condições sistêmicas e institucionais sob as quais se dá o exercício do poder, tais como as características do sistema político, a forma de governo, as relações entre os Poderes, o sistema de intermediação de interesses" (SANTOS, 1997, p. 342).

Se aplicada a situações como a de realização da Oktoberfest (apelo cultural, econômico e social) enquanto política pública que mobiliza e promove acordos, explícitos e subliminares sobre um fim, entre inúmeros atores da esfera da sociedade civil, preconiza suportes e demandas, pode ser considerada como pré-condição relativa à própria razão de existir, endógenas, do evento ante seu significado.

Toda a estruturação necessita de ações sócio-interativas que podem se traduzir como formas de sustentação permitidas por instâncias de governança que poderão ou não traduzir-se em governabilidade ou manutenção de propósitos primordiais de uma política. Neste contexto Mantovaneli Jr. e Sampaio (2007, p. 11), a partir da governança, assim consideram a ideia de sustentabilidade política:

\footnotetext{
$\mathrm{Na}$ medida em que os processos são vistos como determinantes fundamentais da política e seus resultados, estes se tornam, também, alvo privilegiado dos processos decisórios; ou seja, os atores começam a se preocupar com a abordagem aplicada ao processo decisório; suas pedagogias, sua normatividade, suas prerrogativas, sua dinâmica, passando também a deter conhecimento e com ele lidar.
}

As preocupações dos atores sociais obrigatoriamente envolvidos no processo de gestão de uma atividade ou empreendimento, por uma questão existencial, os mesmos necessitam interar-se sobre as decisões para que tenham sobreguardados os seus interesses. Qualquer determinação política resultará em conflitos de interesse entre os 
grupos protagonistas (atores). Cabe à gestão municipal gerir os conflitos e garantir a estabilidade e a ordenação social.

A sustentabilidade administrativa está posta para o homem a partir das demandas da sociedade como descrito por Mantovaneli Jr. (2013). Portanto, a capacidade administrativa efetivamente está alicerçada na capacidade de representação dos gestores, influência exercida sobre um determinado grupo, importante para a compreensão do fato administrativo, assim expressado por Ramos (1983, p. 7):

É um complexo de elementos e de suas relações entre si, resultante e condicionante da ação de diferentes pessoas, escalonadas em diferentes níveis de decisão, no desempenho de funções que limitam e orientam atividades humanas associadas, tendo em vista objetivos sistematicamente estabelecidos.

Está caracterizada nos estudos de Ramos (1983) a definição da origem do fenômeno administrativo como um fenômeno social, passível de uma sociologia própria da capacidade de gestão, portanto no próprio ser humano e na sua natureza, porém com as condicionantes pré-estabelecidas pelos processos produtivos das organizações: funções operacionais e a hierarquização, presentes no fato administrativo (ações do homem, organização, burocracia e as funções). O pesquisador aprofunda-se ainda mais neste raciocínio sobre o homem e a administração: "Basicamente são duas as características do fato social: 1) sua exterioridade em relação a consequências dos indivíduos; 2) a ação coercitiva que exerce ou é suscetível de exercer sobre tais consequências" (DURKHEIM apud RAMOS, 1983, p. 24) ${ }^{2}$. Destas duas afirmativas, surge o conceito que deveria prevalecer no processo de gestão, tanto para o setor público, bem como para o setor privado, que são os destinos da sociedade e suas organizações estatais e privadas: a governança, suas esferas de representatividade como um efetivo instrumento de organização social e defesa do interesse comum. As ações do homem bem como das instituições que representam, têm consequências para a sociedade e delimitando fases, aonde ficam caracterizadas as territorialidades, como nesse grande evento: a Oktoberfest. A seguir será caracterizado melhor esta temática.

\footnotetext{
${ }^{2}$ DURKHEIM, É. As regras do Método Sociológico. 8. ed. São Paulo: Nacional, 1977. 128 p.
} 


\section{TERRITÓRIO E TURISMO}

A caracterização de um território ocorre a partir de muitos fatores que, como consequência, acabam por delimitar as formas de ocupação e utilização de um dado espaço geográfico. Alguns elementos são importantes e complementares uns aos outros, como é o caso das características físicas de uma área, aspectos socioculturais, econômicos, estruturais, a sustentabilidade, legislação, política, outros indiretamente ligados a este setor.

Nem todo lugar é adequado para a exploração da atividade turística. Existem as características específicas que determinam a tipologia turística de um território, caracterizado por Rita de Cássia Cruz (2000, p. 18):

\footnotetext{
Apesar da expansão territorial da atividade turística e da mobilidade espacial de turistas (propiciada pelo progresso dos transportes), há inúmeros lugares no mundo que não foram apropriados pelo turismo. Certa seletividade espacial orienta a eleição, pelo turismo, de determinados pontos do território, em cada momento histórico.
}

O raciocínio da autora traz uma perspectiva de uma seleção mediante atributos físicos naturais, preparação para a atividade (planejamento turístico local), potencialidades culturais, econômico-produtivas e da própria localização geográfica com potencialidades turísticas vizinhas (destinações). Para a inserção do turismo dentro do contexto de um território, é preciso saber o que esta atividade impacta e se destina a fazer em relação a população e a localidade:

O turismo é composto por atividades realizadas pelas pessoas durante viagens e permanência em lugares diferentes do seu local de residência habitual, por um período de tempo consecutivo inferior a um ano, para ócio, negócios e outras finalidades, conforme descreve a Organização Mundial do Turismo (OMT, 2011).

Portanto a atividade acaba impactando com a região, seus meios de produção, pessoas e geografia. Num primeiro plano, a localidade necessita de uma prévia preparação para receber os consumidores do turismo: os turistas. Cada região possui um atributo impar para a exploração turística, como é o caso de Blumenau que dentre várias ramificações do turismo, explora os eventos, estes muito importantes para a economia e 
sociedade blumenauense. No tópico a seguir será verificado este tipo de turismo com maiores detalhes.

\section{TURISMO DE EVENTOS}

Os eventos são importante ferramenta promocional para uma destinação turística, pois o consumo do produto turístico de uma localidade acontece de forma automática durante um evento sediado por um destino turístico. Cabe ao poder público oferecer políticas e fomentar a atividade/segmento em parceria com a iniciativa privada, baseando-se na defesa de seus interesses e principalmente dos munícipes e habitantes do seu entorno (região).

A partir de uma definição oficial da atividade (eventos), baseada na sua metodologia, é possível definir aspectos característicos da Oktoberfest como planificação e conhecimento autóctone, vital para o turismo de eventos, com ênfase nas características étnico-culturais. Eventos como a Oktoberfest, que celebram as características de uma etnia, promovem a união da comunidade em torno de um objetivo comum, além das celebrações culturais germânicas: oportunidades e o desenvolvimento de Blumenau e região, afirmativa esta corroborada por Pellegrini Filho (1993, p. 125):

\footnotetext{
Não vemos como evitar que o visitante se mostre curioso em saborear pratos regionais, em comprar peças artesanais (de confecção tradicional-popular ou de pequenas oficinas), em comparecer a festividade e movido pelo incomum de uma Congada, de uma Cavalhada, de um Boi-Bumbá, de uma Chegança, de um pastoril ou outras manifestações do teatro popular, ou ainda atraído por danças como Frevo, a Ciranda, o Catira, o Batuque de Umbigada etc.
}

As manifestações da cultura de um local em suas várias formas - danças, gastronomia, hábitos e costumes cotidianos - podem alavancar demandas específicas pelos eventos étnico-culturais e a partir daí gerar oportunidades para o desenvolvimento. Portanto, de acordo com as vocações turísticas regionais, em uma das suas principais ramificações, no turismo de eventos é importante observar o papel que a governança exerce a partir de suas ações, bem como nos resultados socioeconômicos obtidos na realização de uma festa. O segmento de eventos possui uma dinamicidade a qual está presente em várias atividades econômicas: na indústria, comércio; gerando turismo a 
partir da organização de eventos para contemplar interesses de cada atividade. A seguir será apresentada a análise do estudo de caso da Oktoberfest e as suas consequências socioeconômicas para a região de Blumenau.

\section{O CASO ESTUDADO E SEU CONTEXTO}

A cidade de Blumenau, situada na Região Sul do Brasil, no estado de Santa Catarina - Região do Médio Vale do Itajaí - com 329.082 habitantes e uma área de 520 km (IBGE, 2010), sedia, ao longo de 30 anos a Oktoberfest, As características germânicas presentes na cultura blumenauense, cultivadas desde a chegada dos primeiros imigrantes alemães, originaram a ideia da realização da festa. A concepção da Oktoberfest em Blumenau surgiu alguns anos antes de seu início, quando empresários da indústria e comércio da cidade, conhecendo a festa alemã, ”já pretendiam a realização de um evento turístico-cultural semelhante aquele" (FERRARI, 1998, p. 19). Um dos fatos marcantes que determinaram finalmente o início da realização da Oktoberfest em Blumenau foi o das enchentes de 1983/1984, as quais destruíram boa parte da cidade, todavia o projeto do evento já existia e seria executado mesmo sem que as catástrofes acontecessem ${ }^{3}$. Sessenta dias após a última cheia, em 5 de outubro de 1984, cria-se a Oktoberfest, com dez dias de festa e público de 102.000 pessoas (PMB, 2013), com o intuito de propiciar oportunidades de negócios e reaquecer a economia de Blumenau após as referidas tragédias. O evento foi viabilizado através de ações conjuntas do poder público e da iniciativa privada. Os objetivos socioeconômicos que efetivaram o início da realização da festa movimentam direta e indiretamente mais de 39 atividades profissionais distribuídas pelos três setores da economia e que geram oportunidades de trabalho para cerca de 4.000 pessoas no período pré e perOktoberfest ${ }^{4}$.

\footnotetext{
${ }^{3}$ Entrevista realizada com Dalto dos Reis In: Santos (2009).

${ }^{4}$ Entrevista realizada com José Carlos Oeschler In: Santos (2009).
} 
QUADRO 1 - EVOLUÇÃO DE PÚBLICO NA OKTOBERFEST

\begin{tabular}{|c|c|c|c|c|c|}
\hline Ano & Público & Ano & Público & Ano & Público \\
\hline 1984 & 102.000 & 1985 & 362.371 & 1986 & 802.230 \\
\hline 1987 & 874.945 & 1988 & 1.009 .057 & 1989 & 954.692 \\
\hline 1990 & 959.998 & 1991 & 844.255 & 1992 & 1.010 .060 \\
\hline 1993 & 853.000 & 1994 & 827.000 & 1995 & 929.793 \\
\hline 1996 & 515.213 & 1997 & 500.245 & 1998 & 500.000 \\
\hline 1999 & 607.417 & 2000 & 616.222 & 2001 & 626.620 \\
\hline 2002 & 502.937 & 2003 & 605.538 & 2004 & 613.184 \\
\hline 2005 & 365.288 & 2006 & 602.941 & 2007 & 690.144 \\
\hline 2008 & 594.636 & 2009 & 731.934 & 2010 & 578.870 \\
\hline 2011 & 563.925 & 2012 & 589.351 & 2013 & 451.523 \\
\hline
\end{tabular}

Fonte: PMB (2013).

Este quadro mostra não somente a simples evolução de público do evento, mas as fases que marcaram a festa. Num primeiro momento, 1984-1988, o evento caracterizou-se não somente com um enfoque empreendedor ou motivador da comunidade, mas pelas características culturais autóctones. Num segundo momento, o evento passou por um estágio em que o interesse econômico prevaleceu, com forte apelo comercial que descaracterizou o intuito étnico-cultural da festa. $\mathrm{Na}$ segunda territorialidade promoções como o Skol-rock (década de 1990) se sobrepuseram ao apelo cultural introduzindo atrativos para que alguns empreendedores da iniciativa privada obtivessem lucratividade com eventos paralelos à Oktoberfest (PMB, 2013). A partir de 2005 houve um resgate da referência inicial da festa, a exaltação comunitária através da cultura germânica, o que estava presente na comunidade (sua história), oportunidades da iniciativa privada e munícipes, além do fortalecimento do poder público e sua aproximação com empreendedores privados e sociedade blumenauense. Com isso, fortaleceram-se os laços entre o 3 atores sociais citados, havendo uma forma de governança na condução da festa, mesmo que este termo não esteja claro fora da academia neste ambiente observado. Nestes termos é possível afirmar, pelas particularidades na utilização do espaço, seus símbolos, objetos e ações (CRUZ, 2000) que a partir desta última fase (terceira), houve uma reterritorialização da Oktoberfest, com um claro enfoque do evento nas tradições desenhadas pelos imigrantes alemães. 


\subsection{RESULTADOS}

Os resultados da pesquisa apontaram que o aspecto governança teve como ponto de convergência a cultura germânica, benéfica e presente nos objetivos de todos os atores sociais. Ou seja, que os elementos autóctones são retomados a partir dos atores com eles envolvidos, seja no planejamento e gestão do evento como em seu cotidiano em outubro, nas atividades fim. Que a festa se fortalece como expressão dos valores de quem a realiza, o que caracteriza elemento de turistificação responsável, e voltava a ocupar um espaço distinto no contexto brasileiro e regional na medida em que reterritorializava com sustentabilidade.

Que com o surgimento de empreendimentos em função da Oktoberfest/Blumenau na cidade e região, por exemplo, na hotelaria, gastronomia e as cervejarias artesanais, e um grande trade com outros festivais do gênero o evento acabava gerando resultados permanentes para a economia e toda a comunidade envolvida. O Turismo de Santa Catarina e Blumenau, amplamente favorecidos pela criação e manutenção deste evento, traz para o poder público benefícios constantes e por isto as barreiras político ideológicas, oriundas da troca de administração na cidade e estado, são esquecidas, pois negligenciar a festa seria um desastre político/administrativo para qualquer gestor público ou partido. No tocante a governança, verificou-se que o arranjo institucional que conduz o evento expressava o entendimento da correlação positiva entre valorização da cultura regional e fortalecimento econômico (e não o inverso).

Dentro desta perspectiva a governança apareceu, mesmo que de forma indireta, explicitada pelos gestores da Oktoberfest nos seus grupos diretivos.

Ficou evidenciada, assim a reafirmação sistemática de todos os segmentos envolvidos na realização do evento com repercussão cultural, social, política e econômica regional. É como aglutinar tendências, interesses e o grau de consciência sobre a necessidade de continuidade da Oktoberfest/Blumenau. Identificou-se que os processos da pactuação que antecede, preside e avalia a festa estavam servindo de elemento comunitário de análise e monitoramento do pela comunidade regional como um todo. 
Dentro da perspectiva da Oktoberfest, o processo de governança da mesma demonstrou-se ocorrer de acordo com cada fase e característica do evento em sua cronologia, conforme observado pelo Sr. Oechsler ${ }^{5}$ :

\begin{abstract}
Se vendia uma situação e na hora o consumidor, o produto Oktoberfest e não encontrava música ou culinária condizente. [...] Havia muita reclamação de turistas [...] nós exigimos que seja tocado um mínimo repertório de músicas germânicas [...] nós cuidamos do aspecto visual das bandas [...] colocamos na cidade grupos músicas nas praças terminais urbanos, nas feiras [...] no ano passado tivemos um público excelente, nós demos uma guinada na festa, deixamos de focar a cerveja, não é mais o carro chefe a cerveja, mas sim a cultura [...] O turista ele sai da sua cidade para ver coisas diferentes. No nosso caso a alegria, um ambiente de festa. Nós colocamos que o turista vai ver aqui um pedaço da Europa, cultura germânica... .
\end{abstract}

Corroborando com esta perspectiva citada pelo dirigente temático da festa, temse a opinião da então Diretora de Planejamento e Desenvolvimento do Turismo de Blumenau, Luisa Helena Siqueira Borda ${ }^{6}$, em entrevista a um dos pesquisadores:

Toda comunidade estava saturada, os dez últimos anos anteriores a 2005 estive poucas dias durante as suas edições, pois era extremamente desagradável o que ocorria e com o rumo que a festa tomava. ... Nós voltamos a gostar de visitar a festa, só ficamos de fora dois dias no ano passado, meus filhos trouxeram os seus amigos de fora para referenciar à cultura local e busca de um ambiente saudável para diversão.

Portanto, considerou-se ter ficado evidenciado que cada período e sua característica traziam uma perspectiva para o evento, determinando, portanto o próprio contemplamento de interesses para cada ator social envolvido ficando claro mais uma vez que a Oktoberfest estava tendo na cultura germânica a peça chave para delimitar a festa e atender aos interesses de comunidade, governo e iniciativa privada.

Observando os aspectos inerentes a territorialidade, foram analisadas as fases distintas do evento, desde a sua criação em 1984 até a edição de 2008 (esta última referência para a fase presente (2013-2014) do evento). De acordo com o ex Prefeito Dalto dos Reis ${ }^{7}$, os fatores determinantes das características de cada uma de suas fases: o caráter comunitário e cultural caracterizou o início do evento, enfatizando as raízes

\footnotetext{
${ }^{5}$ Entrevista realizada com Sr. José Carlos Oechsler In: Silva (2009).

${ }^{6}$ Entrevista realizada com Luisa Helena Siqueira Borda In: Silva (2009).

${ }^{7}$ Entrevista realizada com Dalto dos Reis In: Silva (2009).
} 
germânicas da região de Blumenau, a necessidade da cidade resgatar o seu orgulho enquanto sentimento dos seus moradores e o seu município/região (devido às catástrofes de 1983 e 1984), oportunidade de alavancagem da economia e melhoria da qualidade de vida a partir de renda.

Em síntese, este primeiro momento da Oktoberfest, segundo Dalto dos Reis ${ }^{8}$, vivido nas suas cinco primeiras edições (1984-1988), é caracterizado sobretudo pela valoração cultural, comunitária social e econômica de Blumenau e região.

O segundo momento de delimitação da festa ocorreu a partir de 1989 até meados da década de 2000, quando ocorreu um período de mercantilização do evento no chamado "carnaval alemão", em que atrativos culturais de outras regiões do país eram explorados, desvalorizando a cultura local e o próprio turista que buscava exatamente a cultura alemã oferecida por Blumenau e região. Conforme dados da Prefeitura Municipal de Blumenau (2013), esse período trouxe uma descaracterização da Oktoberfest e fez com que a excessiva massificação do evento acarretasse problemas estruturais para a festa, para atividade turística e para a própria capacidade de carga e fluxo de turistas de Blumenau. Portanto, um período que caracterizou o evento por um grande fluxo de visitantes, descaracterização cultural e negligência dos fatores que motivaram a criação da Oktoberfest/Blumenau.

A terceira e atual (2013-2014) configuração do evento vem ocorrendo desde o ano de 2005, data em que seus gestores e promotores perceberam essa descaracterização e os fatores negativos para a cidade de Blumenau/região e para a Oktoberfest.

Outra consequência importante para a região está na festa como um instrumento de fomento ao desenvolvimento do turismo regional. É importante observar a visão do Ex-Prefeito Dalto dos Reis sobre a contribuição da Oktoberfest/Blumenau para o segmento turístico na região:

Não há como negar que as demais festividades surgidas nos municípios vizinhos, a Marejada, em Itajaí, a Fenarreco, em Brusque, La Sagra, em Rodeio, e tantas outras que poderiam ser mencionadas, mais de 20 no seu total, tiveram a Oktoberfest a sua "festa-mãe, a sua origem." 9

\footnotetext{
${ }^{8}$ Idem.

${ }^{9}$ Idem.
} 
Os gestores do evento, tanto os observados como os do início das festividades da Oktoberfest, manifestaram reconhecer a importância tanto da atividade turística, bem como do evento para a economia, para a comunidade em geral e para a preservação das raízes germânicas da cidade e região, impactando na vida blumenauense e sua sustentação cultural para a sobrevivência da Oktoberfest.

\section{CONSIDERAÇÕES FINAIS}

De acordo com os aspectos da territorialidade apontados pela pesquisa, a Oktoberfest/Blumenau apresentou três momentos distintos e bastante enfatizados pelos atores sociais envolvidos com a festa: uma fase cultural/comunitária dos seus primórdios, seguida por um momento de forte mercantilização e massificação do evento, acarretando em descaracterização da festa e da cultura germânica em meados dos anos de 1990 e, por fim, o resgate cultural, regionalista e comunitário que vem ocorrendo desde o ano de 2005 até o último evento em 2013. Este último retomado inclusive por determinação da nova administração para que o evento voltasse a ter a configuração e a delimitação por consequência deste reavivamento cultural da festa.

Quanto às instâncias de governança identificadas na festa (setor público, comunidade e iniciativa privada), constatou-se a percepção de que existiu um predomínio do poder público à frente das ações que geram governança, como por exemplo, o consenso em torno do resgate e a valorização da cultura alemã. As comissões temáticas da festa, todas elas, de iniciativa do poder público, porém com presença comunitária e da iniciativa privada também, mas as ações partiram de certo diálogo entre a sociedade, governos e iniciativa privada. Contudo, a maior influência foi gerada pela participação da Prefeitura/Vila Germânica. A valorização cultural germânica e a consciência da necessidade de preservação como interesse comum aos atores sociais envolvidos com o evento foi um fato gerado pela instância de governança presente na gestão da festa, sem a precisão da consciência temática (governança) estar presente nas discussões na gestão pública local. 
Quanto à percepção dos atores sociais inerentes aos impactos da Oktoberfest no desenvolvimento turístico regional, é preciso fazer-se uma análise a partir de alguns aspectos: cultural, político, econômico e social.

\section{REFERÊNCIAS}

BOISIER, S. Desenvolvimento local. In: SIEDENBERG, D. R. Dicionário desenvolvimento regional. Santa Cruz do Sul: EDUNISC, 2006.

CARDOSO, T; RIBEIRO (2002) Economia para o homem e desenvolvimento regional: contribuição para um pensamento e uma política regional alternativos. In: BECKER, Dinizar F; BANDEIRA, Pedro S. (Orgs.). Respostas regionais aos desafios da globalização. Santa Cruz do Sul: Edunisc, 2002.

ONU - Organização das Nações Unidas. Nossa comunidade global. Rio de Janeiro: Fundação Getúlio Vargas, 1996.

CRUZ, R. C. Política de turismo e território. São Paulo: Contexto, 2000.

FERRARI, C. L. (Org). Oktoberfest de Blumenau: negócios e oportunidades. Brasília. Ed. SEBRAE, 1998.

IBGE - Instituto Brasileiro de Geografia Estatística. Censo Demográfico 2010. Disponível em:

<http://www.ibge.gov.br/home/estatistica/populacao/censo2010/default.shtm>. Acesso em: $27 / 11 / 2013$.

MANTOVANELI Jr., O. Gestão sustentável (habitus e ação): princípios esquecidos pela agenda do desenvolvimento. Blumenau: EDIFURB, 2013.

MANTOVANELI Jr, O.; SAMPAIO, C. A. C. "Sustentabilidade política e administrativa: contribuições para a reformulação da agenda para o ecodesenvolvimento". Revista de Gestão Social e Ambiental, v. 1, n. 2, mai.-ago., p. 3-21, 2007.

MÜLLER, A. Lazer, desenvolvimento regional: como pode nascer e se desenvolver uma idéia. Santa Cruz do Sul: Edunisc, 2002.

OMT - Organização Mundial do Turismo. Handbook on tourism product development. Madri: World Tourism Organization (UNWTO); European Travel Commission (ETC), 2011.

PELLEGRINI FILHO, A. Ecologia cultura e turismo. Campinas: Papirus, 1993. 
PMB - Prefeitura Municpal de Blumenau. Oktoberfest: história. Disponível em: <http://www.oktoberfestblumenau.com.br/>. Acesso em: 27/11/2013.

RAMOS, A. G. Administração e contexto brasileiro: esboço de uma teoria gral da administração. Rio de Janeiro: Fundação Getúlio Vargas, 1983.

SAMPAIO, C. A. C. Desenvolvimento sustentável e turismo. Florianópolis: Bernúncia, 2004.

SANTOS, M. H. C. Governabilidade, governanca e democracia: criacão da capacidade governativa e relacões executivo-legislativo no Brasil pós-constituinte. In: DADOS Revista de Ciências Sociais. Rio de Janeiro, v. 40, n. 3, 1997. p. 335-376.

SILVA, L. F. Governança e territorialidade no ecodesenvolvimento turístico regional: o caso da Oktoberfest Blumenau. Dissertação (Mestrado em Desenvolvimento Regional). Centro de Ciências Humanas e da Comunicação. Universidade Regional de Blumenau (FURB), 2009.

Recebido em: 28-11-2013.

Aprovado em: 28-12-2013. 